\title{
Massive pulmonary embolism causing large T-wave inversion and QT prolongation
}

\author{
János Tomcsányi, Nóra Turi-Kováts, András Wettstein, Hrisula Arabadzisz \\ Cardiology Department, St. John of God Hospital, Budapest, Hungary \\ Correspondence to: János Tomcsányi, MD. Cardiology Department, St. John of God Hospital, Budapest, Hungary. Email: tomcsanyij@gmail.com.
}

\begin{abstract}
We present a case of massive pulmonary embolism where the electrocardiogram (ECG) demonstrated transient T-wave inversion and marked QT-prolongation. The pathomechanism and clinical significance of these changes are discussed.
\end{abstract}

Keywords: Pulmonary embolism; QT prolongation; T wave inversion

Submitted Sep 20, 2017. Accepted for publication Oct 10, 2017.

doi: $10.21037 /$ jtd.2017.10.89

View this article at: http://dx.doi.org/10.21037/jtd.2017.10.89

\section{Clinical vignette}

A 49-year-old man was admitted to our hospital with a two-week history of exertional dyspnea. He was a daily smoker but otherwise, he had no significant past medical history. Two weeks prior to admission he sprained his ankle which he self-treated it with ice packs. On the day of presentation, he also experienced exertional chest pain which resolved at rest. His physical examination findings were normal except for a fast heart rate. Blood pressure was $131 / 85 \mathrm{mmHg}$, heart rate $120 / \mathrm{min}, \mathrm{O}_{2}$ saturation $94 \%$ on room air. The electrocardiogram (ECG) on admission is shown in Figure 1A. Laboratory studies revealed an elevated D-dimer of $4.61 \mu \mathrm{g} / \mathrm{mL}$ (normal, $<0.5 \mu \mathrm{g} / \mathrm{mL}$ ), slightly elevated NT-proBNP-t of 1,829 pg/mL (normal, $<170 \mathrm{pg} / \mathrm{mL}$ ) and significantly elevated hs-troponin $\mathrm{T}$ of $312 \mathrm{ng} / \mathrm{L}$ (normal, <14 ng/L).

Doppler echocardiogram showed a dilated right ventricle and an estimated pulmonary artery systolic pressure of $68 \mathrm{mmHg}$ (normal, <25 $\mathrm{mmHg}$ ). Doppler ultrasound of the lower extremities revealed a left popliteal vein thrombus. CT pulmonary angiography showed extensive bilateral lower lobe pulmonary emboli. Since the patient remained hemodynamically stable, he did not meet the criteria for thrombolysis and treatment with low molecular weight heparin was initiated. The day after presentation the ECG showed dramatic new changes while there was no significant change in the patient's clinical condition (Figure 1B).

Coronary angiography showed clear coronary arteries, and his echocardiogram remained unchanged. The large T-wave inversion and QT prolongation noted in the second ECG gradually resolved in three days (Figure 1C).

A Viskin test was performed to exclude silent long QT syndrome, and it was normal. Repeat echocardiogram prior to leaving the hospital showed improving right ventricular dilation and a slightly lower pulmonary artery systolic pressure of $46 \mathrm{mmHg}$. The NT-proBNP also decreased to $341 \mathrm{pg} / \mathrm{mL}$.

\section{Description of the ECGs}

The ECG on admission (Figure 1A) shows sinus tachycardia with an S1-Q3-T3 pattern, incomplete right bundle branch block and $\mathrm{T}$ wave inversion in V4. These are classic signs indicating pulmonary embolism. ECG on the following day showed significant QT/QTc prolongation and extensive T wave inversion (Figure 1B) similar to what has been described as global $\mathrm{T}$ wave inversion. However, in our case and in previously published cases on acquired long QT syndrome (LQTS) following PE, there were positive $\mathrm{T}$ waves in leads I and aVL (1). Despite the ECG differences between acquired LQTS and classic global $\mathrm{T}$ wave inversion, the pathomechanism behind them is most probably similar and is related to catecholamine surge, as was hypothesized by Walder and Spodick (2). The exact cause of the prolonged 


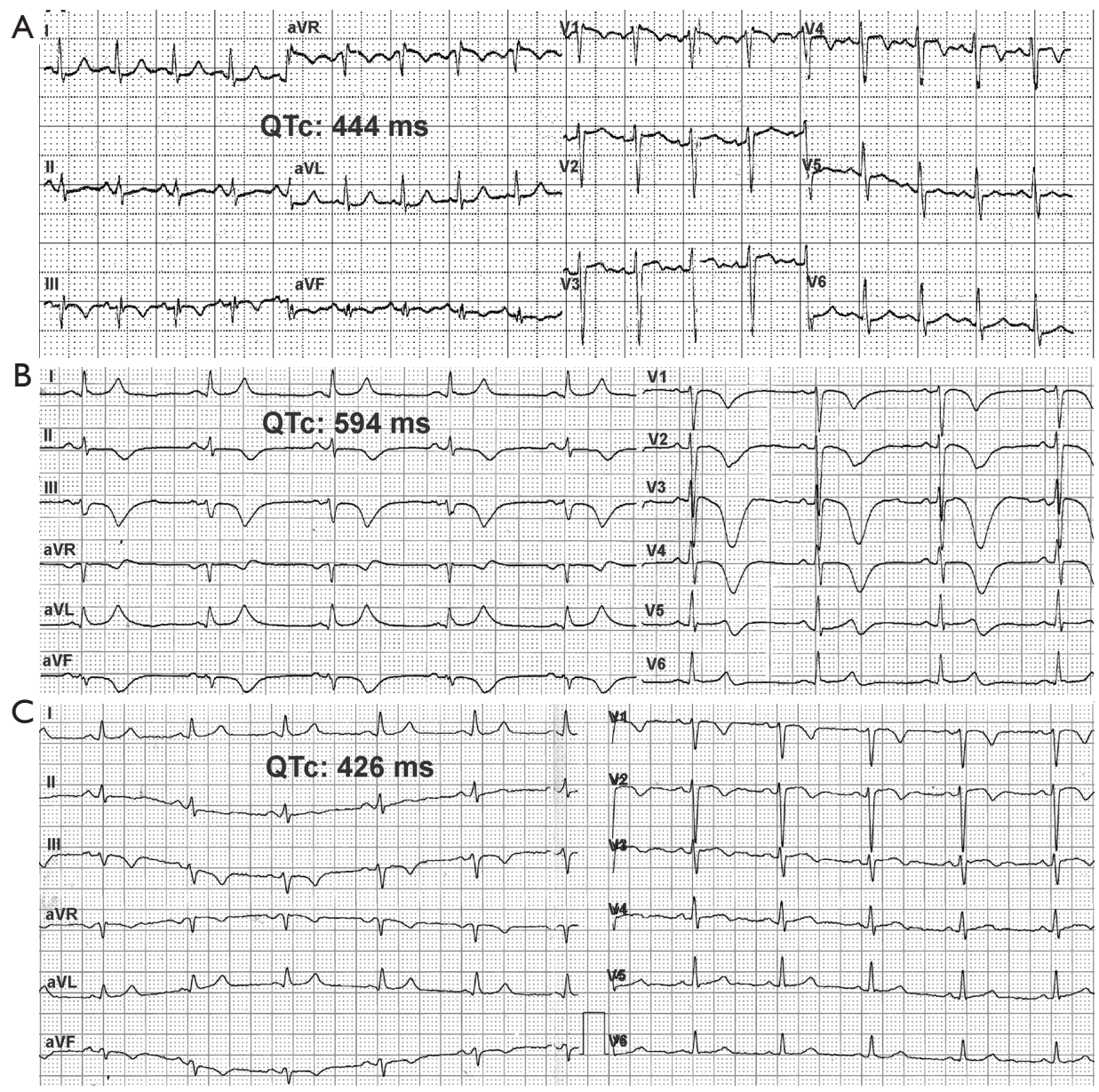

Figure 1 Serial ECG of the patient at presentation (A), next day (B) and three days later (C). ECG, electrocardiogram.

QT and T wave inversion, however, is uncertain and it is also unclear why they only present in select patients.

Recent studies did not find a direct link between QT prolongation and pulmonary embolism outcome (3), however the prolonged QTc group demonstrated significantly increased right ventricular dilatation and systolic dysfunction/stunning (3). Our case also supports this observation.

We entertained the possibility of underlying silent LQTS as a reason for the remarkable QT/QTc prolongation, however the Viskin test-after the resolution of the ECG changes (Figure 1C)—did not support this hypothesis. The kinetics of QT prolongation was similar to the QT prolongation usually seen in stress related cardiomyopathy, but in our case no left ventricular wall motion abnormality was noted. The QT prolongation appeared to be benign as it did not lead to malignant arrhythmias such as torsade de pointes ventricular tachycardia.

\section{Points to ponder}

Biomarkers are not always helpful in the differential diagnosis of dyspnea and chest pain.

Our case of massive pulmonary embolism also highlights the usefulness of the ECG as a cheap and noninvasive bedside method which can help avoid diagnostic errors and incorrect interpretations of elevated troponin levels.

Massive pulmonary embolism can cause significant QT prolongation and T-wave inversion. However, in contrast to global $T$ wave inversion, the $T$ wave remains positive not only in aVR, but also in the high lateral leads I and aVL.

This phenomenon is transient and appears to have no independent prognostic significance. Ongoing research and a recent meta-analysis, however, suggest that the ECG 
in general can be a valuable tool in the prognostication of pulmonary embolism (4) and in identifying a subgroup of patients who are at a high risk of cardiogenic shock (5).

\section{Acknowledgements}

None.

\section{Footnote}

Conflicts of Interest: The authors have no conflicts of interest to declare.

\section{References}

1. Punukollu G, Gowda RM, Khan IA, et al. QT interval prolongation with global T-wave inversion: a novel ECG

Cite this article as: Tomcsányi J, Turi-Kováts $\mathrm{N}$, Wettstein A, Arabadzisz H. Massive pulmonary embolism causing large T-wave inversion and QT prolongation. J Thorac Dis 2017;9(11):4671-4673. doi: 10.21037/jtd.2017.10.89 finding in acute pulmonary embolism. Ann Noninvasive Electrocardiol 2004;9:94-8.

2. Walder LA, Spodick DH. Global T wave inversion. J Am Coll Cardiol 1991;17:1479-85.

3. Digby GC, Kukla P, Zhan ZQ, et al. The value of electrocardiographic abnormalities in the prognosis of pulmonary embolism: a consensus paper. Ann Noninvasive Electrocardiol 2015;20:207-23.

4. Qaddoura A, Digby GC, Kabali C, et al. The value of electrocardiography in prognosticating clinical deterioration and mortality in acute pulmonary embolism: A systematic review and meta-analysis. Clin Cardiol 2017. [Epub ahead of print].

5. Kukla P, McIntyre WF, Fijorek K, et al.

Electrocardiographic abnormalities in patients with acute pulmonary embolism complicated by cardiogenic shock. Am J Emerg Med 2014;32:507-10. 